\title{
Does Ageratina riparia Affect the Regeneration of Forest Species in Disturbed Montane Forests in the Knuckles Forest Reserve?
}

\author{
Rupasinghe W.P.A." , Gunaratne A.M.T.A. and Perera G.A.D. \\ Department of Botany, Faculty of Science, University of Peradeniya, Peradeniya, Sri Lanka \\ *prabharupasinghe@yahoo.com
}

\begin{abstract}
The invasive herb Ageratina riparia (Regel) R. M. King \& H. Rob. (Asteraceae) which is a noxious weed in many countries including Hawaii, New Zealand and Australia is spreading rapidly in the forest gaps, edges and along the footpaths inside disturbed montane forests in KFR. Since A. riparia forms a thick mat in the ground layer of montane forests, its spread can have a detrimental effect on the establishment of seedlings of forest species. Six forest gaps and four footpaths inside a disturbed montane forest were sampled to investigate the effect of A. riparia on the regeneration of the montane forest species. Soil moisture content, soil root density and canopy openness were also determined. Soil seed bank experiments were carried out during wet and dry seasons. The percentage cover of $A$. riparia decreased significantly when moving away from the centre of the footpaths $(\mathrm{P}=0.001, \mathrm{~F}=9.78,0 \mathrm{~m}=62.5 \%, 5$ $\mathrm{m}=6.9 \%, 10 \mathrm{~m}=11.3 \%)$ and the forest gaps $(\mathrm{P}<0.001, \mathrm{~F}=25.54$, centre $=75 \%$, edge $=19.75 \%$, $5 \mathrm{~m}$ away $=0.17 \%$ ) into the forest interior. The mean density of seedlings of forest species showed a negative relationship with percentage cover of $A$. riparia. The mean density (forest gaps; centre $=2.8 \mathrm{~m}^{-2}$, edge $=7.5 \mathrm{~m}^{-2}, 5 \mathrm{~m}=5.8 \mathrm{~m}^{-2}$, footpaths; $0 \mathrm{~m}=2.65 \mathrm{~m}^{-2}, 5 \mathrm{~m}=6.5 \mathrm{~m}-2,10$ $\mathrm{m}=6.12 \mathrm{~m}^{-2}$ ) and the species diversity of forest species decreased with the increased $A$. riparia cover. The root density and root moisture content of forest species was lower in areas where the root density of A. riparia is higher. The soil moisture content in all the locations was nearly equal at all distances from the centre of the gaps and footpaths into the forest $(\sim 2)$. The canopy openness was higher in the forest gaps than the footpaths $(\mathrm{P}<0.001, \mathrm{~F}=27.48)$. According to the results, growth and establishment of $A$. riparia is determined by the quality of light. Seedling emergence of A. riparia from soil seed bank was higher during the dry season than the wet season. Lower number of forest seedlings emerged in the locations where high emergence of $A$. riparia seedlings was recorded. However according to the statistical analysis there was no relationship between the number of A. riparia seedlings and the seedlings of tree and shrub species that emerged from the soil seed banks (forest gaps; $\mathrm{R}^{2}=0$, Footpaths $\left.\mathrm{R}^{2}=0.005\right)$. Since native forest species including Psychotria zeylanica and Symplocos cochinchinensis showed high seedling densities even with high A. riparia cover. They can be used to restore disturbed submontane forest patches invaded by A. riparia at KFR.
\end{abstract}

Keywords: Ageratina riparia, Knuckles Forest Reserve, Forest regeneration, Forest gaps, Footpath 